\title{
Cell death at the intestinal epithelial front line
}

\author{
Maria Eugenia Delgado, Thomas Grabinger and Thomas Brunner \\ Chair of Biochemical Pharmacology, Department of Biology, University of Konstanz, Germany
}

\author{
Keywords \\ apoptosis; cell death; chemotherapy; \\ intestinal epithelial cells; irradiation; \\ necroptosis; tumour necrosis factor

\section{Correspondence} \\ T. Brunner, Biochemical Pharmacology, \\ Department of Biology, University of \\ Konstanz, Universitätsstrasse 10, 78457 \\ Konstanz, Germany \\ Fax: +497531885372 \\ Tel: +497531885371 \\ E mail: thomas.brunner@uni konstanz.de
}

\begin{abstract}
The intestinal epithelium represents the largest epithelial surface in our body. This single-cell-layer epithelium mediates important functions in the absorption of nutrients and in the maintenance of barrier function, preventing luminal microorganisms from invading the body. Due to its constant regeneration the intestinal epithelium is a tissue not only with very high proliferation rates but also with very prominent physiological and pathophysiological cell death induction. The normal physiological differentiation and maturation of intestinal epithelial cells leads to their shedding and apoptotic cell death within a few days, without disturbing the epithelial barrier integrity. In contrast excessive intestinal epithelial cell death induced by irradiation, drugs and inflammation severely impairs the vital functions of this tissue. In this review we discuss cell death processes in the intestinal epithelium in health and disease, with special emphasis on cell death triggered by the tumour necrosis factor receptor family.
\end{abstract}

\section{Introduction}

The total number of cells present during the life of a multicellular organism is highly regulated by cell division and, importantly, also by non-accidental and non-pathological pathways of cell death. Cells which are no longer required by the organism auto-induce their own death by activating tightly controlled intracellular cell death mechanisms known as programmed cell death. This process is especially important in organs like the gut, where high proliferative cell rates coexist with a high rate of cellular demise in order to maintain healthy tissue homeostasis and organ functionality. In addition, a large number of microbes and bacteria, largely exceeding that of total cells in the human body, reside in close proximity to the intestinal epithelium. Therefore programmed cell death may also play an essential role as a self-protective mechanism by preventing infected cells from persisting or even proliferating, and thereby disseminating potential pathogens, while maintaining proper barrier function of the rest of the intestinal epithelium. It is noteworthy that an imbalance of these processes is involved in the pathogenesis of a number of intestinal diseases, such as inflammatory bowel disease (IBD) and intestinal tumour development [l 1 5].

The concept of programmed cell death was first described in 1964 in a study of insect tissue development [6] and later further developed in mammalian cells [7]. Since then, two major pathways of

\footnotetext{
Abbreviations

cFLIP, cellular FLICE inhibitory protein; DcR, decoy receptor; DISC, death inducing signalling complex; FADD, Fas associated death domain; GvHD, graft versus host disease; IAP, inhibitor of apoptosis protein; IBD, inflammatory bowel disease; IEC, intestinal epithelial cell; IEL, intraepithelial lymphocyte; LPS, lipopolysaccharide; MAPK, mitogen activated protein kinase; MOMP, mitochondrial outer membrane permeabilization; NF $\kappa B$, nuclear factor $\kappa B$; RIP, receptor interacting protein; TJ, tight junction; TNFR1, TNF receptor 1 ; TNF, tumour necrosis factor; TRADD, TNFR associated death domain; TRAIL, TNF related apoptosis inducing ligand; TWEAK, TNF related weak inducer of apoptosis.
} 
programmed cell death have been identified: apoptosis and necroptosis. Apoptosis is a well-defined cell death subroutine based on the coordinated action of a family of aspartic-acid-specific proteases called caspases, whereas necroptosis is a caspase-independent mechanism of cell death which seems to be dependent on the activity of the receptor-interacting protein (RIP) kinase family [8]. Some reports also described a type of programmed cell death with features of autophagy. However, it is still a matter of debate as to whether autophagy rather represents a survival mechanism, or whether autophagy or another cell death mechanism is actually responsible for this cell death [9]. Apoptosis is the primary programmed cell death response to cellular stress, while necroptosis is considered as a safe but rather rough alternative when apoptosis is impaired or blocked, e.g. in virally infected cells. Moreover, and in contrast to apoptosis, necroptosis leads to the rupture of cell membranes leading to the release of cytoplasmic factors and induction of inflammation. Although necroptosis is often only seen when apoptosis, i.e. caspase activity, is blocked, the intestinal epithelium is a good example where necroptosis plays a critical role in cell death associated with developmental defects due to genetic deletions in mice [10 13], e.g. when caspase-8 is deleted (see further discussion below). Thus, the scientific community has developed an increasing interest in this subject in order to decipher the mechanisms and roles of this cell death pathway in vivo [14].

In this review we aim to focus on the specific biochemical mechanisms of apoptotic cell death implicated in physiological and pathophysiological intestinal epithelial cell (IEC) functions. However, considering the importance of the crosstalk of different cell death subroutines, especially in IECs after tumour necrosis factor (TNF) stimulation $[9,15,16]$, other non-apoptotic mechanisms of cell death will be briefly discussed. Of note, the study of IEC death in physiological scenarios represents a challenge by itself. Although a large number of cells die daily in the intestinal epithelium, a limited number of dying cells can be observed under homeostatic conditions, probably due to the fast cell turnover and their clearance [17]. This mechanism greatly increases the efficiency of the epithelial barrier function; however, it limits the study of cell death under normal steady-state conditions. In this regard, the advantages and disadvantages of the different models and methodology used in the studies cited here will be briefly discussed. Finally, the purpose of this review is to highlight the current knowledge and remaining open questions in the study of IEC death (see Box 1), in order to give a more complete understanding of the complexity of the signal transduction that regulates the
Box 1: Highlights

Facts

- In the intestinal epithelium high proliferative rates coexist with high cellular demise contributing to maintenance of epithelial barrier function.

- Apoptotic cell death plays a relevant role in the physiological tissue turnover as well as pathophysio logical damage of the intestinal epithelium.

- The fate of IECs is regulated by a complex interplay between proliferation and survival signals on one hand and apoptosis and necroptosis on the other.

- Disturbance of these processes can result in chronic inflammation and lethality.

- The detailed understanding of TNF dependent cell death mechanisms in IECs will help in the develop ment of specific therapies for the treatment of intestinal immunopathologies.

Open questions

- Why are IECs more susceptible to TNF stimulation than other tissues and cells and what is the biologi cal benefit of this susceptibility?

- What is the relevance of necroptosis in the mainte nance of physiological epithelial functions and the pathophysiological damage of the epithelium?

normal physiological as well as pathological cell demise in the intestinal epithelium.

\section{Structure and function of the intestinal epithelium}

The small and large intestine (colon) are specialized tubular structures within the abdominal cavity responsible for the digestion of food and the absorption of ions, water, nutrients, vitamins and unconjugated bile salts. No less important is their protective barrier function against gut microbes and other non-microbial content in the intestinal lumen, including enzymes, gastric acid or pancreatic juice [18]. The boundary between these luminal contents and the tissue compartments of the gastrointestinal tract is known as the intestinal epithelial layer, which represents the largest surface of the body in direct contact with the external environment [19].

The intestinal epithelial layer is a polarized singlecell-layer epithelium composed of different cell types. Absorptive epithelial cells, or enterocytes, are columnar cells that constitute the majority of the IECs. 
Tight junctions (TJs), containing proteins such as occludins and claudins, and adherence junctions, consisting of cadherin or nectin, are junctional complexes that connect epithelial cells to each other, supporting the polarity of the epithelial layer and the maintenance of effective barrier function. Different signalling pathways can modulate these tight intracellular seals, as shown in studies with different epithelial cell lines. For instance, kinases like the mitogen-activated protein kinase (MAPK) family or protein kinase A are able to regulate the expression of $\mathrm{TJ}$ proteins, thereby modulating the paracellular permeability of the epithelium [20]. In the same way, changes in the expression of some TJ proteins have been shown to regulate cellular mechanisms, such as differentiation, cell growth or apoptosis, among others (reviewed in [20]). Therefore, these junctions play an important role in the maintenance of the epithelial barrier integrity as well as in cell-to-cell communications. However, the complete pathways have not yet been defined [21] and, due to the limitations of cultured cell lines, further research is required in order to elucidate the role of TJ-dependent regulation in the in vivo context. In addition, the epithelial layer is covered with a thick mucus layer, derived from goblet cells, interspersed between the absorptive epithelial cells. This mucus layer permits efficient absorption of nutrients while inhibiting diffusion of large molecules and adherence of luminal bacteria to the epithelial layer [22]. Accordingly, the mucus layer contributes to the proper maintenance of intestinal barrier function. In certain intestinal conditions, such as shock, increased gut permeability has been observed in association with the disruption of this layer $[23,24]$. The protective importance of the mucus layer is also illustrated by the development of spontaneous bacterial-driven colitis in mice with MUC2 mucin deficiency, a main component of the mucus layer [25].

Other cell types composing the intestinal epithelium are the pyramidal-shaped Paneth cells, generally observed under physiological conditions at the bottom of the small intestinal crypts, or under inflammatory conditions also in the colon. These cells contain eosinophilic granules, whose anti-microbial content, e.g. lysozyme and defensins, helps to prevent bacterial infection of the intestinal crypts [19,23,26]. Besides Paneth and goblet cells, enteroendocrine cells also represent secretory cells of the intestinal epithelium. They represent $1 \%$ of total epithelial cells and their main function is the secretion of hormones, which coordinate digestion and metabolism [19,27]. An interesting cell type frequently found in the intestinal epithelium are so-called intraepithelial lymphocytes (IELs), a unique population of mostly $\mathrm{CD}^{+} \mathrm{T}$ lymphocytes located within the epithelial cell layer outside of the basal lamina of the intestinal mucosa. IELs seem to be involved in the host defence, but particularly in immune regulation and tissue preservation due to their capacity to secrete immunoregulatory epithelium preserving cytokines $[19,28]$. However, their exact role in maintaining intestinal immune homeostasis is still under debate [29].

The intestinal epithelium is a columnar single-cell layer organized in crypts and villi which project into the lumen; and it is common along the small and large intestine. However, differences in morphology and cell distribution can be observed between large and small intestine, and even along the different parts of the small intestine such as the duodenum, jejunum or ileum (proximal distal sections with 20\%, 40\% and $60 \%$ of total area, respectively). For instance, the villus structure is present only in the small intestine and amplifies the surface area up to fourfold (jejunum), compared to the colon. Despite structural differences, a common feature along the intestine is the strikingly fast renewal of the epithelial lining. Interestingly, small subpopulations of undifferentiated stem cells are the main source of this process. The epithelial stem cells are located in the lower part of the crypt close to its base $(+4$ position or the stem cell zone [30]) and differentiate either towards the base of the crypt into Paneth cells and enteroendocrine cells or upwards towards the villus into absorptive epithelial cells and goblet cells [19]. These crypt stem cells are the main engine driving the selfrenewing property of the intestinal epithelium by generating new cells that then migrate to the bottom of the crypts or to the villus tip, where they are finally removed by shedding into the lumen [30]. The proliferation rate of the stem cells and migration rate of the differentiated cells depends on external factors, such as hormones and growth factors [19]. This is a continuous physiological process, leading to a complete renewal of all intestinal differentiated cells every 26 days, except for Paneth cells and stem cells $[31,32]$. The loss of cells at the villus tip by shedding into the lumen is a highly regulated and complex process that contributes to the gut barrier function and maintains the organ functionality [23].

\section{Mechanism of IEC shedding during homeostasis}

Excessive epithelial cell loss or decreased regenerative capacity results in a lack of epithelial layer integrity leading to an increase in the intestinal barrier permeability, promoting the leakage of potential hazardous 
substances and microorganisms into the body. However, despite the very high turnover of cells in this organ, a healthy intestinal mucosa is able to maintain the integrity of the epithelium and gut barrier function by the continuous production of new epithelial cells compensating the loss of mature epithelial cells at the villus tip by shedding. The loss of mature epithelial cells was traditionally believed to be maturation-driven, possibly due to the lack of space at the tip of the villi. Nevertheless, this mechanism is far from being a simple passive process and increasing evidence suggests that it is a complex sequence of orchestrated events that seem necessary to maintain the continuity of the epithelium and the gut barrier function. In this regard, the mechanism by which epithelial cells are shed from the tip of the villus into the lumen is fundamental for understanding intestinal homeostasis in health and disease [23]. However, as cell viability of primary ex vivo cultured IECs is very low [33] and transformed epithelial cells are a poor substitute to study the biology of IECs, the lack of suitable mouse models makes the study of physiological IEC shedding and homeostasis in healthy organisms rather complicated. Thus, the precise mechanism is still poorly understood. Nonetheless, in vivo microscopy studies of the small intestine in anaesthetized mice, or in humans, by using confocal endomicroscopy with intravenous fluorescent probes were able to shed some light in this field [23,34,35]. Cells to be shed alter TJs and integrins in order to be able to detach from the basal membrane and neighbouring cells and to start the cell extrusion [36]. However, the nature of the stimuli that alter the TJs in the first place in a homeostatic situation of the epithelium is still under debate. Studies employing in vivo cell tracking suggested that once the contact between neighbouring cells is weakened unknown forces are able to push shedding cells out of the monolayer. Moreover, some authors suggested that due to differences in migration speed these forces might be independent of the pressure exerted from the movement of cells going towards the villus [37]. Once the cell leaves the monolayer, the adjacent cells extend their cytoplasm underneath the shedding cell, creating new junctional elements that maintain the epithelial continuity [23,36,38]. Interestingly, although the local barrier function remains intact, several studies have described the existence of certain gaps in the epithelium once the cells are shed [34,37,39]. Apparently, this is possible since the cell-free gaps in the epithelial monolayer are sealed with an impermeable substance, whose nature and origin is still unknown [40]. Finally, the cell being extruded undergoes a detachment-dependent apoptotic cell death [23]. Thanks to this mechanism of cell death, old epithelial cells are removed from the intestinal mucosa without triggering an inflammatory response. However, further research is required in order to completely define the mechanism of IEC shedding during homeostasis, in particular regarding the role of detachment-induced apoptosis in this mechanism [23,41].

\section{Detachment-induced apoptosis in IECs}

Differentiation-triggered shedding of aged IECs at the villus tip, or shedding of stressed IECs from the basal membrane of the epithelial layer, leads to activation of the main executors of apoptosis, the caspase family, which has been shown to occur alongside the typical cell extrusion morphology [2,23,42,43] (Fig. 1). Interestingly, IECs show differential apoptosis sensitivity depending on their degree of differentiation [44]. The luminal surface of the epithelium and the crypt region are the more susceptible sites to undergo apoptosis. In general, crypt cells seem to be more resistant to spontaneous apoptosis induction than mature villus IECs, probably also due to the longer lifespan of crypt cells compared to mature villus epithelial cells [2]. Under steady-state conditions apoptotic cells in the intestinal crypts are rarely observed (Fig. 1). A completely different situation, however, is seen under pathological conditions, where crypt cells seem to be a sensitive target of many apoptosis-inducing triggers $[45,46]$.

Detachment of IECs leads to a caspase-dependent form of cell death, called anoikis. Similarly, various apoptosis triggers, including TNF, can promote massive shedding of IECs resulting in cell death. At present it is not fully understood whether in this stress-induced form of anoikis the shedding process initiates the apoptosis induction, or whether the initiation of apoptosis and caspase activation is the trigger of cell detachment from the basal membrane and neighbouring cells. But probably the latter is more relevant for stress-induced detachment and associated apoptosis as, after TNF injection or other stressors, cleaved caspase-3-positive cells are already observed at a stage when they are still fully integrated in the epithelial layer (Fig. 1). Noteworthy, in the case of TNF-induced cell extrusion, apoptosis precedes shedding that occurs as a secondary event; however, due to the technical problems already discussed, the relevance of this mechanism in healthy intestine has not been described [39]. Depending on the type of trigger, anoikis or apoptosis induction leading to shedding of mature IECs can be mediated by the intrinsic as well as the extrinsic apoptosis pathway $[9,47]$. For example, detachment of adherent epithelial cell line cells and IECs has been reported to lead to a Bcl-2 family-mem- 


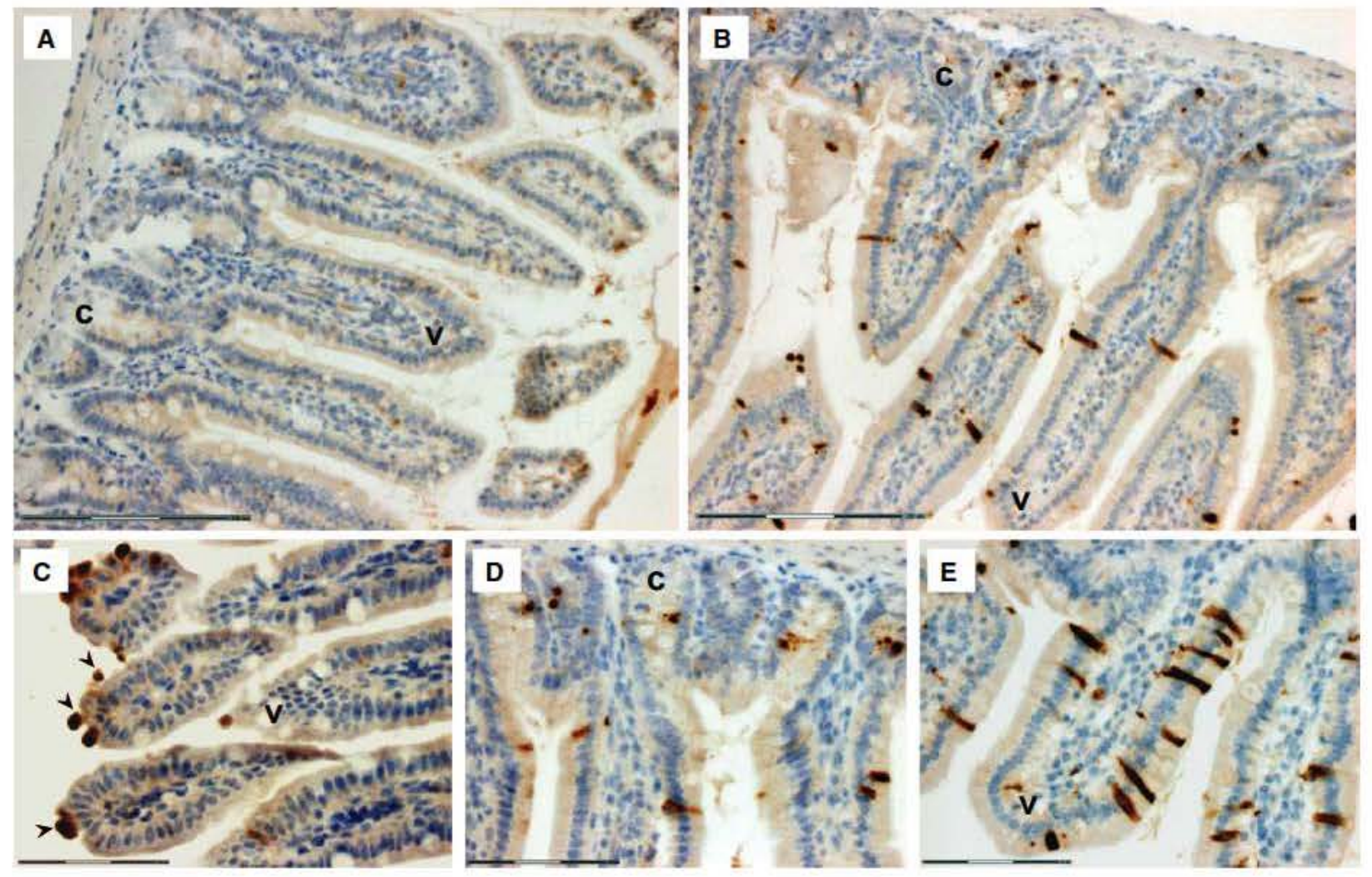

Fig. 1. Apoptosis in the intestinal epithelium. Staining for cleaved caspase 3 of the small intestine of (A) control treated mouse, (B) chemotherapeutic drug treated mouse with apoptotic crypt and villus epithelial cells. (C) Details of villus cross section with apoptotic and shed IECs (arrows). (D) Details of apoptotic crypt cells. (E) Details of apoptotic villus IECs. C, crypts; V, villus. Scale bar $150 \mu$ m (A, B) or $75 \mu \mathrm{m}(\mathrm{C} E)$.

ber-dependent form of cell death (e.g. involving the BH3-only proteins Bmf and Bim) [48,49], whereas TNF can also trigger apoptosis of mature IECs and their detachment from the epithelial layer via activation of TNF receptor 1 (TNFR1) [17,50]. Of note, although the chronology of events and the proteins implicated in cell shedding induced by these distinct pathways are quite different, crosstalk between them has been reported, generally leading to an amplification of death-receptor-induced signal via activation of the mitochondrial pathway [51 53].

The intrinsic or also called the mitochondrial pathway of apoptosis can be triggered by different stimuli, such as DNA damage or genotoxic stress. These stress signals converge at the mitochondrial membranes by promoting the formation of pores that cause the permeabilization of the mitochondrial outer membrane (MOMP) and the release of proteins from the intermembrane space to the cytosol with lethal consequences for the cell. Therefore, mitochondria and their regulation play an essential role in the control of apoptosis execution by the intrinsic pathway. In this regard, the Bcl-2 family proteins are the critical regulators of the mitochondrial pathway and MOMP. This family of structurally related proteins includes both pro- and anti-apoptotic members and can be activated by either transcriptional or post-translational mechanisms in response to survival signals or cellular stress [54 56]. The Bcl-2 family proteins have been shown to play an essential role in the regulation of IEC apoptosis and survival under physiological and pathophysiological conditions [ 56 58]. For instance, the proapoptotic BH3-only protein Bim is upregulated in response to detachment of the non-transformed small intestinal epithelial cell line IEC-18, where it associates with the pro-survival $\mathrm{Bcl}-2$ member Bcl-xL and promotes anoikis [49]. Similarly, its close relative Bmf has been associated with IEC anoikis [59]. Accordingly, other studies in non-malignant rat and human IECs support the relevant role of $\mathrm{Bcl}-\mathrm{xL}$ in regulating anoikis $[60]$.

Following MOMP, the release of pro-apoptotic proteins, such as cytochrome $c$ and Smac/DIABLO, from the mitochondria into the cytoplasm induces several 
cellular processes considered as the 'point of no return' in cell fate [61]. Once cytochrome $c$ is released, it promotes the oligomerization of a heptameric complex called the apoptosome [62 64]. In turn, procaspase-9 binds to this complex where it becomes auto-activated, thereby promoting downstream caspase activation and apoptosis execution [65].

On the other side, the death receptor pathway of apoptosis, also known as the extrinsic pathway, is a very well established mechanism, which involves the activation of the TNF receptor superfamily and has been shown to play an important role in anoikis $[60,66,67]$. The apoptosis-inducing members of the TNF receptor family, the so-called death receptors, are membrane sensors that are able to detect their specific cognate ligands ('death ligands'), which promote signals leading to cellular destruction [68]. Various human and mouse death receptors have been identified thus far. Among them, Fas/CD95 (APO-1), TNFrelated apoptosis-inducing ligand receptor 1 (TRAILR1/death receptor 4 or DR4), TRAILR2 (DR5/APO-2/KILLER) and TNF receptor 1 (TNFR1/ p55/CD120a) are the best-studied receptors [68]. Their specific activation with their structurally related cognate ligands results in the recruitment of adaptor molecules, inducing either cell death or pro-survival signals $[69,70]$.

In the death receptor pathway, apoptosis events occur mainly after the formation of the death-inducing signalling complex (DISC), the caspase-activating platform for the apical caspase-8. Activation of the DISC depends on the bipartite adaptor molecule Fas-associated death domain (FADD) and results in the recruitment and proteolytic maturation of procaspase8 [71,72]. Recent publications revealed the stoichiometry of the DISC core components, providing an explanation of a previously described phenomenon of filament formation after death effector stimulation [73]. Further studies nicely described that instead of the suggested $1: 1$ FADD : procaspase- 8 ratio, up to ninefold more caspase- 8 than FADD can be found in the DISC as procaspase- 8 molecules interact sequentially to form a caspase-activating chain $[74,75]$. The length of these procaspase- 8 chains was reported to be variable and dependent on various factors, such as the strength of death receptor stimulation, the available pool of procaspase- 8 in the cell and the presence and abundance of the catalytically silent caspase- 8 homologue, the cellular FLICE-inhibitory protein (cFLIP) [74,75]. Therefore, cFLIP is a potent inhibitor of death-receptor-induced apoptosis, since it competes with procaspase- 8 for binding to the DISC [76]. In this regard, cFLIP appears to be of particular relevance for the regulation of IEC apoptosis, since genetic deletion of cFLIP in the murine intestinal epithelium leads to perinatal lethality, which seems to be at least in part dependent on TNFR1-induced IEC apoptosis [77]. Furthermore, cFLIP expression in IECs is upregulated in patients with IBD, probably as an attempt to prevent death-receptor-induced apoptosis during the course of intestinal inflammation [78].

Besides cFLIP-mediated regulation of caspase- 8 activation, other potentially important mechanisms of death-receptor-induced apoptosis regulation in IECs are decoy receptors (DcRs). These receptors are homologues of the TNF receptor family and compete for their binding to the ligands [69]. For instance, the cell surface molecules DcR1 and DcR2 have been found to bind TRAIL and to antagonize TRAIL-induced apoptosis, whereas the soluble DcR3 binds and antagonizes FasL [70]. Critically, these receptors are either not membrane receptors, as in the case of DcR3, or lack an intracellular death domain and thus cannot promote the recruitment of signalling molecules such as FADD and procaspase- 8 , ultimately promoting apoptosis. Therefore, by competing for binding to their respective ligands, they can negatively regulate deathreceptor-induced apoptosis [69,70]. Of interest, high levels of DcR3 have been identified in the colonic mucosa of patients with ulcerative colitis or Crohn's disease, suggesting a potential protective response against FasL-mediated damage of the intestinal epithelium [79 81]. However, it is at present not completely clear what the relevance of FasL-induced IEC apoptosis is during IBD (reviewed in [79]).

Ultimately, both the intrinsic and the extrinsic pathways of apoptosis lead to the activation of apical caspases promoting the processing and activation of downstream effector caspases. Among the effector caspases caspase- 3 is the protease responsible for the cleavage of the majority of the apoptotic substrates $[82,83]$. Thus, clearly regulation of caspase activity is a central process in apoptosis control. Molecules that either directly or indirectly control caspase activation and/or activity may also play a critical role in IEC apoptosis. In this regard, members of the inhibitors of apoptosis protein (IAPs) family have received increasing scientific interest due to their proposed novel function as regulators of the balance between life and death signals in the intestinal epithelium. Among the eight human IAPs identified so far, the X-linked inhibitor of apoptosis (XIAP), the cIAP1 and the cIAP2 are the best characterized [84]. XIAP is of all IAPs the only one that exerts its apoptotic inhibitory function by direct binding to the catalytic domain of caspases, while cIAP1 and cIAP2 seem to be more efficient in 
inhibiting apoptosis through their ubiquitin ligase activity [85]. Interestingly, detachment of the non-malignant highly anoikis-susceptible intestinal epithelial cell line IEC-18 has been shown to trigger upregulation of XIAP and cIAP2 proteins, thus delaying anoikis and providing a regulatory mechanism for cell extrusion [86].

Therefore, the integrity of the biochemical pathways leading to IEC anoikis or apoptosis are extremely important in order to maintain a healthy intestinal epithelium. Moreover, mutations resulting in the perturbation of these mechanisms may contribute to different intestinal pathologies, including complete destruction of the intestinal epithelial layer and subsequent death on one side of the extreme or anoikis resistance promoting carcinoma progression on the other side [87].

\section{Pathophysiological conditions promoting excessive IEC apoptosis}

Continuous physiological cell death in combination with high proliferation rates of IECs contributes to the striking self-renewing properties of the epithelial layer, maintaining proper intestinal barrier function and preventing the accumulation of damaged and potentially transformed cells. On the other hand, excessive cell death induction in mature IECs and crypt cells may cause a massive breakdown of this homeostatic process, disrupting this epithelial barrier, with the subsequent entry of noxious agents and aberrant stimulation of the intestinal immune system. Excessive IEC apoptosis is initiated by a rather diverse pattern of stimuli, which can be generally grouped into (a) immune-cell-derived triggers, (b) drugs and (c) physical stressors (Fig. 2). As mentioned above, the intestinal epithelium is one of the tissues with the highest proliferation rate due to constant renewal of the epithelium. Since stem cells and transient amplifying cells in the crypts are proliferating and synthesizing DNA, they are also more sensitive to treatments leading to DNA damage. Thus, it is not surprising that the intestinal epithelium is one of the most sensitive tissues to DNA-damage-inducing treatments. These include irradiation and chemotherapeutic drugs. Consequently, gastrointestinal complications are among the most frequent side effects of cancer therapy. Of interest, DNA-damage-induced apoptosis in IECs is mostly found in the intestinal crypts, in agreement with the proliferative stage of intestinal stem and progenitor cells; however, it is also seen in mature terminally differentiated epithelial cells in the villus, which do not undergo cell cycle progression
[46]. This indicates that probably different chemotherapy- and irradiation-induced apoptosis pathways are induced in crypt and villus IECs.

Among the immune-cell-derived triggers, members of the TNF family and their initiation of the death receptor pathway of apoptosis appear to play a dominant role in IEC apoptosis in the context of inflammatory processes of the intestine. Immunopathological conditions which lead to damage of the intestinal epithelium include IBD, bacterial and viral infections, intestinal graft-versus-host disease (GvHD) and sepsis. Common to all of these disorders is that excessive immune cell stimulation leads either to the development of cytotoxic effector functions, which directly cause epithelial damage, or to the systemic or local expression of soluble TNF family members, which then promote apoptosis in IECs. In intestinal GvHD donor-derived allospecific cytotoxic $\mathrm{T}$ cells infiltrate the intestinal mucosa and directly kill IECs via cell-mediated cytotoxic effector functions, such as perforin and FasL [88,89]. Similar cytotoxic effector mechanisms may be responsible for immunecell-mediated damage to the intestinal epithelium during intestinal infections with viruses [90]. In contrast, IEC apoptosis and epithelial damage observed during systemic immune cell activation (e.g. by sepsis) or during IBD appear to be largely mediated by soluble members of the TNF family. In this regard it is important to stress that, while in most cell types and tissues TNF fails to promote apoptosis but rather leads to activating and pro-survival signals, the intestinal epithelium is exquisitely sensitive to the apoptosis-inducing activity of TNF. TNF injection or strong systemic TNF induction upon injection of lipopolysaccharide (LPS) into mice rapidly promotes IEC shedding and apoptosis in mature and crypt IECs [17]. Likely more chronic processes of TNFinduced IEC apoptosis also occur during experimental colitis in mice or IBD in human patients, as neutralization of TNF has a strong therapeutic effect and results in reduced tissue damage, mainly due to the inhibition of cell death but also due to the downregulation of pro-inflammatory processes that might contribute to local tissue damage [91,92]. Further details on how TNF family members promote IEC apoptosis will be discussed below.

\section{DNA-damage-induced apoptosis in IECs}

The use of pharmacological drugs and irradiation in cancer therapy aims at specifically killing tumour cells while sparing normal tissue cells. However, due to the 


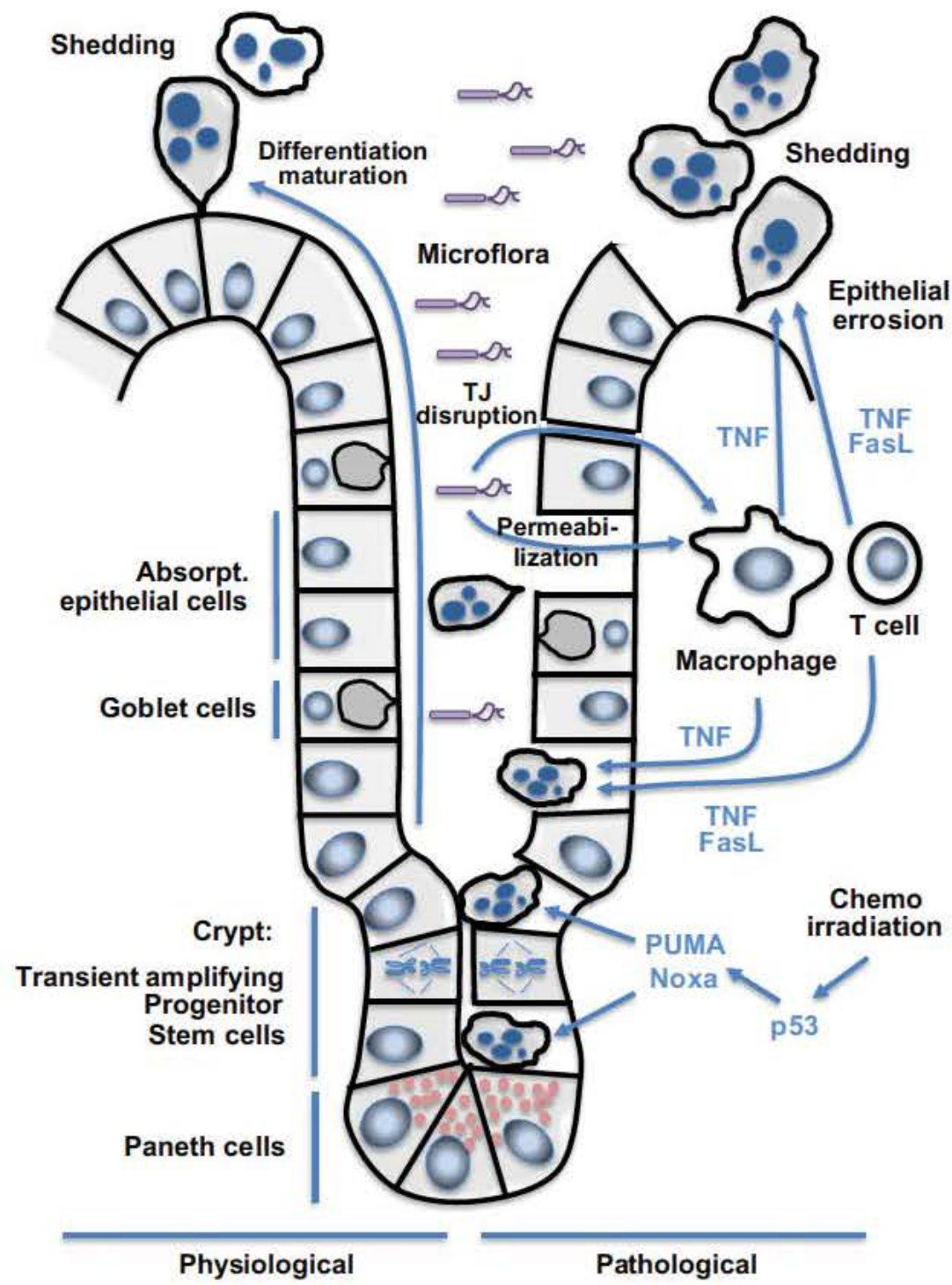

Fig. 2. Cell death induction in the intestinal epithelium under physiological and pathological conditions. Intestinal stem cells and transient amplifying progenitor cells differentiate into Paneth cells, goblet cells or absorptive epithelial cells. These migrate within a few days to the villus tip, where they are shed into the lumen. Chemotherapy or irradiation particularly targets proliferating crypt cells by inducing DNA damage, which leads to p53 PUMA/Noxa dependent apoptosis. Activation of macrophages and $T$ cells leads to TNF and FasL expression, which promotes apoptosis in mature epithelial cells and crypt cells. Cell death and TNF mediated disruption of TJs promotes access of immune cells to the luminal microflora, stimulation of inflammatory processes and further induction of IEC apoptosis. high proliferative capacity and apoptosis sensitivity, these treatments often lead to massive intestinal epithelial injury causing diarrhoea, general malabsorption and infection [93]. These effects significantly limit the effective dose of the chemotherapeutic agents, while at the same time they cause an extremely discomforting situation for cancer patients [94]. While the therapyevoked infection may also be caused by drug- or irradiation-induced cell death in bone marrow cells and associated immune suppression, diarrhoea and malabsorption are directly related to a treatment-induced damage of the intestinal epithelium. Similarly, an increase in the epithelial permeability may also result in increased bacteria penetrating the intestinal mucosa, leading to systemic infection and potentially to sepsis. Due to their high proliferative potential, crypt cells are the cells within the intestinal epithelium that are most susceptible to DNA damage and cell death after chemotherapy. This inappropriate loss of crypt cells results in an intestinal mucosal damage called 'mucositis'. Chemotherapy-induced mucositis is characterized by crypt loss, villus atrophy, as well as impairment of the gut absorptive and barrier functions [95].

The coordinated action of DNA repair mechanisms, transcriptional regulation and apoptosis constitute the DNA damage response and help to limit these devastating effects [96]. The DNA repair mechanisms are tightly regulated by cell cycle, cyclin-dependent kinases and their inhibitors, coordinating the repair processes, as well as cell cycle arrest allowing time to repair the DNA $[96,97]$. Depending on the type of DNA lesions and the cell cycle phases, different mechanisms 
are involved in the repair of damaged DNA [96]. If successful, cells survive and return into cell cycle.

However, in the case of persistent or excessive DNA damage where the repair machinery is not able to repair the lesions, cell death is induced [98]. The tumour suppressor gene and transcription factor p53 plays an important role in the regulation of DNAdamage-induced cell death [99]. In particular, p53 has been shown to be critical for irradiation-induced apoptosis in the intestinal epithelium [100,101]. The p53 protein has been implicated in the regulation of the transcription of genes encoding pro-apoptotic members of the Bcl-2 family, such as PUMA [102], Noxa [103], Bim [104], Bax [105], but also anti-apoptotic members, such as Mcl-1 [106]. While under steady-state conditions p53 constantly becomes ubiquitinated and degraded by the proteasome, upon induction of DNA damage p53 becomes stabilized and undergoes posttranslational modifications that modulate its activation [107]. Many, if not most, apoptosis-promoting activities of $\mathrm{p} 53$ are mediated via the transcriptional control of apoptosis-regulating target genes. In particular PUMA and Noxa appear to be the most relevant target genes in the p53-mediated response to DNA damage. These $\mathrm{BH} 3$-only proteins seem to mediate p53-dependent apoptotic pathways in response to DNA damage in most cellular systems, including IECs [108]. PUMA induction has also been shown to contribute to the pathogenesis of inflammation-dependent colitis $[109,110]$, implicating p53 in the regulation of epithelial homeostasis also under inflammatory conditions. However, as p53-dependent upregulation of the TNF receptor family and activation of the caspase-8dependent pathway has also been described [111,112], it is feasible to consider that not all p53-regulated cell death is mediated via the induction of BH3-only proteins. Furthermore, it should also be noted that irradiation-induced crypt cell apoptosis still occurs in p53-deficient mice [113], suggesting the induction of alternative apoptosis pathways. In this regard it is interesting that its close relative p73 also regulates the transcription of the Bcl-2 homologues Bax, PUMA and Noxa [101,104,114] and may thus represent a backup mechanism for p53 in irradiation-induced IEC apoptosis.

Current knowledge regarding the role of p53 in DNA-damage-induced IEC death is mostly based on studies in whole-body-radiated mice [94]. Interestingly, the role of p53 in apoptosis seems to be dependent on the degree of radiation and is reported to be irrelevant in spontaneous apoptosis [101]. Even with severe radiation treatment, studies with knockout animals suggested a dual role for p53 in DNA-damage-induced
IEC apoptosis [94,115]. p53 was proposed to have a pro-apoptotic role around $24 \mathrm{~h}$ after radiation, due to the transcriptional upregulation of proteins such as Bax, Bak and PUMA, which promote tissue destruction. However, at a later stage $(96120 \mathrm{~h}$ post radiation), the p53-dependent induction of proteins involved in the cell cycle arrest and DNA repair mechanism inhibits IECs to undergo lethal mitotic catastrophe. This observation suggests a higher relevance of the p53-dependent inhibition of mitotic cell death and cell cycle arrest in radiation-induced DNA damage than in regulating apoptosis, questioning the applications of p53 inhibitors in some therapeutic scenarios [115].

Considerable efforts are currently focused on the development of small molecules that help to counteract the side effects of chemotherapy-induced DNA damage in the intestinal epithelium. In this regard, the development of new techniques such as the three-dimensional culture of intestinal organoids, containing intestinal stem cells as well as differentiated progeny cells, may thus represent a most interesting screening system for pharmacological drugs and toxins with higher relevance for human patients than in vitro studies with cell lines or in vivo studies in mouse models [46].

\section{Immune-cell-driven IEC apoptosis}

The plethora of inflammatory disorders that directly or indirectly affect the integrity and the function of the intestinal epithelium already strongly supports the notion that IECs are a prime target of numerous immune-cell-derived cytotoxic effector molecules. This is the case when either immune cells become locally activated or activated immune cells infiltrate the intestinal mucosa (e.g. in intestinal GvHD, colitis or local viral or bacterial infections), but also upon strong systemic activation of the immune system. For example, injection of LPS into mice triggers systemic immune cell activation, specifically macrophages which, indirectly and probably via soluble immunecell-derived factors, trigger excessive apoptosis in the intestinal epithelium. Similarly, induction of sepsis promotes a strong systemic inflammation, which also causes massive IEC apoptosis. Of interest, there is a direct correlation between the extent of epithelial damage associated with sepsis and sepsis-mediated lethality [116], indicating how important intestinal epithelial barrier integrity is and how vulnerable the intestinal epithelium is to apoptosis induction. This extreme sensitivity of the epithelium to cell-death-promoting stressors is probably a trade-off for an efficient uptake of nutrients and a constant renewal of the epithelial layer. Although numerous immune-cell-derived 
effector molecules have a potential to do harm to IECs, there is strong evidence that members of the TNF superfamily play a central role in the induction of epithelial damage by apoptosis.

Three members of the TNF family are known for their apoptosis-inducing properties, i.e. TNF, FasL and TRAIL. In contrast, only weak apoptosis-inducing activities have been described for their homologue TWEAK (TNF-related weak inducer of apoptosis), although TWEAK signalling may still have a strong impact on apoptosis induction by other triggers [117]. Upon activation, $\mathrm{T}$ cells, and in particular $\mathrm{CD} 8^{+}$cytotoxic $\mathrm{T}$ cells, readily express FasL on their cell surface and can promote apoptosis in Fas-sensitive target cells. Injection of a T-cell-activating antibody into mice leads to systemic $\mathrm{T}$ cell activation, including activation of intestinal $\mathrm{T}$ cells. This treatment results in severe epithelial damage, which is at least in part mediated by FasL-mediated killing of IECs [118]. Interspersed within the epithelial layer the intestinal mucosa contains a large number of mostly $\mathrm{CD}^{+}$IELs. Although these cells are generally not cytotoxic, it has been shown that their activation leads to FasL expression and FasL-mediated cytotoxicity. Importantly, during intestinal GvHD, the intestinal epithelial layer is strongly infiltrated by alloreactive donor-derived cytotoxic $\mathrm{T}$ cells, which cause severe damage to the host epithelium by promoting FasL/Fas-mediated apoptosis [89,119]. FasL-mediated epithelial damage has also been implicated in a murine model of experimental colitis, where reduced epithelial damage and inflammation was observed in the absence of the Fas receptor (lpr mice) [120]. Surprisingly, however, Fas receptor signalling may also have an opposite, rather cytoprotective, effect on IECs in other models of murine colitis [121]. Very likely this observation on the protective function of Fas signalling on IEC apoptosis and experimental colitis is related to a more recently recognized activity of the Fas receptor to induce MAP kinases and nuclear factor $\kappa \mathrm{B}(\mathrm{NF}-\kappa \mathrm{B})$ activation, and thereby promote pro-survival pathways and the expression of pro-inflammatory cytokines [122]. Of interest, nonlymphoid FasL expression has also been reported in IECs, specifically in Paneth cells, even though it appears not to promote IEC apoptosis but rather contributes to the deletion of activated $\mathrm{T}$ cells [123]. Thus, FasL has a rather broad spectrum of biological activities in the intestinal epithelium, ranging from cell death-promoting to survival-promoting activities.

The TNF family member TRAIL has gained strong scientific and commercial interest due to its presumably restricted apoptosis-inducing activity in tumour cells $[124,125]$. However, there is accumulating evidence that TRAIL may also trigger activating, prosurvival signals in tumour cells [126] and that the proapoptotic activity of TRAIL is not restricted to tumour cells but extends also to primary tissue cells. In this context it is of interest that TRAIL fails to directly promote apoptosis in hepatocytes, but appears to have an enhancing effect on other death triggers $[52,127,128]$. TRAIL and TRAIL receptor expression have been described in the intestinal epithelium, and altered expression patterns and TRAIL sensitivity have been associated with viral infections [129] and IBD [130]. Of interest, TRAIL and TRAIL receptor appear to be co-expressed in colonocytes under normal conditions without evidence of autocrine apoptosis induction. Thus, the precise role of TRAIL in regulating IEC apoptosis in health and disease remains to be elucidated.

The founding member of the TNF family, TNF, is probably the best-documented inducer of cell death in the intestinal epithelium, not only of apoptotic cell death but also of the more recently characterized necroptosis. This is rather surprising as in most tissues and cells TNF fails to induce apoptosis in the absence of sensitizers, such as inhibitors of transcription or protein synthesis. In these tissues TNF rather promotes activating, pro-survival and pro-inflammatory signals, as discussed above. In this respect the intestinal epithelium represents a rather lonesome exception. Although TNF has been implicated in the induction of tissue damage in other tissues under inflammatory conditions (e.g. experimental hepatitis) [131], the intestinal epithelium represents the most sensitive tissue to the direct action of TNF, in the absence of an acute or chronic inflammation [17,50]. Furthermore, TNFinduced IEC apoptosis and tissue destruction have been implicated in a number of inflammatory conditions affecting the intestinal mucosa. IBD is the bestcharacterized inflammatory disorder of the intestinal mucosa involving TNF as a major effector mechanism of tissue destruction. Various mouse models of experimental colitis (although not all) [132] depend on TNF. For example, the well-characterized 2,4,6-trinitrobenzenesulfonic acid hapten-induced and the CD4 ${ }^{+}$

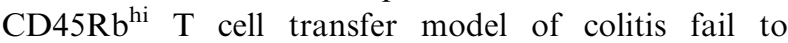
develop in the absence of TNF [133,134]. Similarly, TNF is a major target in human IBD, and neutralizing TNF using recombinant antibodies has strong therapeutic success [91]. Although TNF probably contributes to the regulation of various aspects of inflammation, including the induction of chemotactic cytokines, adhesion molecules and the recruitment of immune cells, TNF-induced epithelial damage represents a critical aspect of the pathogenesis of colitis. In 
this regard TNF has a dual action. Next to disturbing the integrity of the epithelial layer by inducing apoptosis in IECs, TNF also leads to the disruption of TJs $[43,135]$, increasing the permeability of the epithelial layer, providing access to immunostimulatory bacterial products and further fuelling inflammation and tissue destruction.

The underlying reason why IECs are so exquisitely sensitive to the cell-death-promoting activity of TNF is at present largely unexplored. It has been well documented that the TNF receptor responsible for transducing cell death in IECs is TNFR1 [50]. Similarly, it is clear that the direct cell-death-inducing activity of TNF involves caspases, as in vivo treatment with caspase peptide inhibitors blocks IEC apoptosis [50]. In most cells TNFR1 rarely induces DISC assembly and caspase activation, but only when alternative signalling pathways are blocked [70,136]. After being activated TNFR1 can recruit via death domain interactions the alternative adaptor protein TNFR-associated death domain (TRADD), inducing the assembly of other signalling complexes like complex I and II [70,136,137]. Complex I is formed by the interaction of the ubiquitin ligases TNFR-associated factor-2 (TRAF2), cIAP1 and 2, and RIPK1 with the adaptor protein TRADD $[138,139]$. Following polyubiquitylation of RIPK1 by cIAP1 and 2 the IKK kinase complex (IKK $\alpha, \beta$ and $\gamma / \mathrm{Nemo}$ ) is recruited to the receptor complex, and this in turn activates NF- $\mathrm{KB}[137,140,141]$. In addition, TNFR1 is also able to activate MAP kinases via TRAF2-mediated recruitment of the MAPK 7 [141].

TNF-induced activation of MAP kinases and the $\mathrm{NF}-\kappa \mathrm{B}$ signalling pathways have been shown to play a relevant role in IEC homeostasis, especially in inflammatory disorders of the intestine [78,142,143]. Besides its role in cell activation and survival, NF- $\mathrm{B}$ signalling also promotes the release of pro-inflammatory cytokines such as TNF [144]. Of interest, also IECs are able to produce TNF and thereby regulate intestinal inflammation in an autocrine manner [145]. However, Guma et al. showed that the persistent activation of the NF- $\mathrm{B}$ pathway was not sufficient to cause epithelial damage and barrier dysfunction alone, but additional MAP kinase pathway activation is required [142]. This observation supports the protective role of intestinal epithelial NF- $\mathrm{B}$ activation, mostly due to its ability to inhibit IEC apoptosis and prevent epithelial barrier disruption [78,142,146].

Complex II is formed when RIPK1 is deubiquitinated by CYLD. The resulting signalling complex is then dissociated from the receptor and released to the cytosol, where FADD and caspase- 8 can bind and initiate apoptosis (complex IIa) [137,138,147]. However, the chronology and requirements of these steps are still not fully understood [137]. Considering the exquisite susceptibility of the intestinal epithelium to TNFdependent apoptosis, TNFR1-induced formation of complex IIa appears to be a default pathway in IECs and to proceed most efficiently. And evidently this TNF-induced signalling pathway is of major relevance for the maintenance of epithelial homeostasis in the gut [145]. The underlying molecular basis for this susceptibility is thus far not fully understood. But given the fact that cIAP1 and 2 are important switch factors in the regulation of various signalling outcomes after TNFR1 activation, they probably play an important role in the regulation of IEC sensitivity to TNF. Some hints about the relevance of cIAPs in this process come from observations by Vince et al. [148] and Wicovsky et al. [149], who demonstrated that the weak apoptosis inducer TWEAK sensitizes various cell lines to TNF-induced apoptosis and necroptosis. This sensitizing effect was attributed to the TWEAK-induced degradation of cIAP1 and TRAF2, resulting in an acceleration of pro-death pathways. Of interest, a recent study on the regulation of TNF-dependent damage of the intestinal epithelium during acute GvHD described that neutralization of TWEAK using a soluble Fn14 receptor substantially reduced intestinal epithelial damage and lethality [117]. In this study we also showed that direct TNF-mediated IEC apoptosis is significantly reduced when TWEAK is neutralized. These findings suggest that cIAPs may indeed play a central role in the regulation of IEC sensitivity to TNF-induced apoptosis. Supporting this notion, we observed that intestinal organoids are sensitized to TNF by TWEAK co-treatment or IAP inhibition ( $T$. Grabinger \& T. Brunner, unpublished results).

Finally, it should be mentioned that although the extrinsic apoptosis pathway as mediated by TNF family members appears to have a dominant role in immune-cell-mediated epithelial damage, there is evidence that the intrinsic pathway also contributes to IEC apoptosis under inflammatory conditions. In this regard it has been observed that deficiency of the BH3-only protein Bmf leads to reduced epithelial damage and associated disease in a model of experimental colitis [59].

\section{Necroptosis in TNF-stimulated IECs}

TNF may induce not only activating signals of apoptosis but also a second form of cell death, necroptosis, with substantial differences from apoptosis. After TNF stimulation, next to complex I and IIa, a third complex (complex IIb or necroptosome [150]) may form 
[151]. Interestingly, in this case TNF leads to rather necrotic types of cell death features. Deubiquitination of RIPK1 by CYLD directly recruits FADD, caspase8, cFLIP and an additional RIPK1 family member, RIPK3, via RIP-homotypic interaction domains and independently of TRADD, to trigger necroptosis [151 154].

The formation of complex IIa or IIb mainly depends on the levels of cFLIP and caspase-8. Complex Idependent NF- $\kappa B$ activation induces the expression of cFLIP [155], thus preventing complex II-dependent caspase- 8 activation and promoting cell survival $[138,156,157]$. However, if cFLIP expression is inhibited, for instance by accelerating its degradation after stress signals, such as JNK activation [158], complex II will promote caspase- 8 activation and apoptosis. In this case, active caspase- 8 cleaves and inactivates RIPK1, and thus prevents RIPK1 RIPK3 interaction and the formation of the necroptosome [159]. In contrast, if caspase- 8 activity is inhibited, the complex IIb will assemble and RIPK1/RIPK3-dependent necroptosis is induced [16]. Therefore, the ratio cFLIP/caspase8 activation determines the cellular outcome after TNF stimulation. Moreover, in the intestinal mucosa, cFLIP represents a major switch regulating survival, cell death and tissue homeostasis [77].

At present the role of necroptosis in epithelial cell death under physiological conditions or epithelial damage during immunopathological diseases is incompletely understood and quite controversial. Thus far, little evidence is available whether administration of TNF in vivo would promote necroptosis in IECs alone or in parallel to apoptosis. In fact, upon administration of TNF or strong induction of TNF expression upon LPS injection caspase-mediated apoptosis appears to be the dominant form of cell death, and caspase inhibition by zVAD-fmk prevents IEC detachment and cell death [50]. Of interest, however, necroptosis appears to have a major importance in the regulation of inflammation and intestinal tissue damage observed in mice with specific deletions of components of the TNFR1 signalling complex. Although RIPK1, caspase- 8 and FADD are not required for the embryonic development of the intestinal mucosa and the intestinal epithelium in particular, mice with IEC-specific deficiencies in these genes develop severe intestinal inflammation, which is dependent on intestinal colonization by commensal bacteria, probably stimulating immune cells and mediated by TNF. Thus, the extensive epithelial erosion and inflammation as a consequence of caspase- 8 and FADD deletion could be abrogated by deleting either TNF or RIPK3, indicating that necroptosis is primarily responsible for this massive damage of the intestine. Interest- ingly, although IEC-specific deletion of RIPK1 also results in intestinal epithelial damage, this appears to be rather mediated by apoptosis. Thus caspase- 8 deficiency could rescue the inflammatory phenotype of IECspecific RIK1-deficient mice, but not RIPK3 deletion [160]. Therefore, while caspase- 8 activity regulates RIPK1 and RIPK1/RIPK3-mediated necroptosis, RIPK1 appears to have also a regulatory role on the TNF-induced activation of caspase- 8 and apoptosis. This regulatory role of RIPK 1 seems to be independent of its kinase activity, but rather depends instead on its platform function [160]. In summary, necroptosis appears to promote cell death in the intestinal epithelium predominantly when apoptosis induction via the TNF receptor is impaired.

As stated above, many of these massive immunopathologies observed in mice with IEC-specific gene deficiencies of the TNF signalling pathway only develop after colonization of the intestinal lumen by commensal bacteria. This is of interest as also induction of experimental colitis in mouse models is often dependent on the bacterial microflora. Furthermore, antibiotic treatment also has a therapeutic effect in the remission of patients with IBD (reviewed in [161]). This indicates that the intestinal microbiome is able to trigger inflammatory processes, which if proceeding in an uncontrolled manner lead to devastating responses. In this regard it is interesting that members of the pathogen recognition receptor (PRR) family can also induce necroptosis [150]. Considering the huge bacterial load in the intestinal tract, it is tempting to speculate that IEC necroptosis may represent a host defence mechanism against invasive bacteria. Cells of the innate immune system express PRRs, such as plasma membrane or endosomal membrane associated Tolllike receptors, and cytosolic NOD-like receptors that sense pathogen-associated molecular patterns (PAMPs) contained in viral or bacterial nucleotides, lipoproteins, LPS or peptidoglycans [162]. Studies in several cell lines showed that activated PRRs after PAMP exposure can lead to the induction of the inflammatory response as well as the activation of necroptosis $[150,163]$. These PAMP receptors are differentially expressed in IECs [164]. Thus, necroptosis via PAMP receptors may represent a relevant mechanism of intestinal cell death induction contributing to epithelial homeostasis and, if deregulated, to intestinal inflammation and intestinal disorders [2].

\section{Concluding remarks}

In summary, the intestinal epithelium is a tissue where cell proliferation and physiological and pathophysiological 
cell death go hand-in-hand, contributing to tissue homeostasis and function. The intestinal epithelium is also a tissue where different forms of cell death, i.e. apoptosis and necroptosis, coexist, although apoptosis appears to be responsible for physiological cell death whereas apoptosis and necroptosis account for pathophysiological cell death in the epithelium. The exquisite sensitivity of the intestinal epithelium to apoptosis induction appears to be a price to be paid in order to facilitate efficient nutrient uptake and at the same time maintain tissue homeostasis and prevent bacterial and viral infections and/or the development of tumours. Last but not least, a perfect equilibrium between prosurvival and cell-death-promoting signals is a prerequisite for a dynamic homeostasis in the intestinal epithelium. Upcoming development of new methodologies and model systems that overcome the difficulties involved in the study of IEC turnover under homeostatic conditions will help us to better understand the mechanisms regulating this complex equilibrium, allowing the development of potential therapeutic applications.

\section{Acknowledgements}

This work was supported by grants from the German Science Foundation to T.B. T.G. received a $\mathrm{PhD}$ fellowship from the RTG1331 Graduate School.

\section{Conflicts of interest}

The authors declare no competing financial interests.

\section{Author contributions}

TB and MED wrote the manuscript, while TG provided helpful discussions. The final revision of the manuscript was performed by MED with the helpful supervision of TB, who finalised the manuscript.

\section{References}

1 Peppelenbosch MP \& van Deventer SJ (2004) T cell apoptosis and inflammatory bowel disease. Gut $\mathbf{5 3}$, 15561558.

2 Gunther C, Neumann H, Neurath MF \& Becker C (2013) Apoptosis, necrosis and necroptosis: cell death regulation in the intestinal epithelium. Gut 62, 10621071.

3 Doering J, Begue B, Lentze MJ, Rieux Laucat F, Goulet O, Schmitz J, Cerf Bensussan N \& Ruemmele FM (2004) Induction of T lymphocyte apoptosis by sulphasalazine in patients with Crohn's disease. Gut 53, 16321638.
4 Gao C \& Wang AY (2009) Significance of increased apoptosis and Bax expression in human small intestinal adenocarcinoma. J Histochem Cytochem 57, 1139 1148.

5 Watson AJ (2004) Apoptosis and colorectal cancer. Gut 53, 17011709.

6 Lockshin RA \& Williams CM (1964) Programmed cell death II. Endocrine potentiation of the breakdown of the intersegmental muscles of silkmoths. $J$ Insect Physiol 10, 643649.

7 Kerr JF, Wyllie AH \& Currie AR (1972) Apoptosis: a basic biological phenomenon with wide ranging implications in tissue kinetics. Br J Cancer 26, 239257.

8 Green DR, Oberst A, Dillon CP, Weinlich R \& Salvesen GS (2011) RIPK dependent necrosis and its regulation by caspases: a mystery in five acts. Mol Cell 44, 916.

9 Galluzzi L, Vitale I, Abrams JM, Alnemri ES, Baehrecke EH, Blagosklonny MV, Dawson TM, Dawson VL, El Deiry WS, Fulda S et al. (2012) Molecular definitions of cell death subroutines: recommendations of the Nomenclature Committee on Cell Death 2012. Cell Death Differ 19, 107120.

10 Sakamaki K, Inoue T, Asano M, Sudo K, Kazama H, Sakagami J, Sakata S, Ozaki M, Nakamura S, Toyokuni S et al. (2002) Ex vivo whole embryo culture of caspase 8 deficient embryos normalize their aberrant phenotypes in the developing neural tube and heart. Cell Death Differ 9, 11961206.

11 Varfolomeev EE, Schuchmann M, Luria V, Chiannilkulchai N, Beckmann JS, Mett IL, Rebrikov D, Brodianski VM, Kemper OC, Kollet O et al. (1998) Targeted disruption of the mouse Caspase 8 gene ablates cell death induction by the TNF receptors, Fas/Apo1, and DR3 and is lethal prenatally. Immunity 9, 267276.

12 Welz PS, Wullaert A, Vlantis K, Kondylis V, Fernandez Majada V, Ermolaeva M, Kirsch P, Sterner Kock A, van Loo G \& Pasparakis M (2011) FADD prevents RIP3 mediated epithelial cell necrosis and chronic intestinal inflammation. Nature 477, 330334.

13 Gunther C, Martini E, Wittkopf N, Amann K, Weigmann B, Neumann H, Waldner MJ, Hedrick SM, Tenzer S, Neurath MF et al. (2011) Caspase 8 regulates TNF alpha induced epithelial necroptosis and terminal ileitis. Nature 477, 335339.

14 Tait SW, Ichim G \& Green DR (2014) Die another way non apoptotic mechanisms of cell death. $J$ Cell Sci 127, 21352144.

15 Yuan J \& Kroemer G (2010) Alternative cell death mechanisms in development and beyond. Genes Dev 24, 25922602.

16 Oberst A \& Green DR (2011) It cuts both ways: reconciling the dual roles of caspase 8 in cell death and survival. Nat Rev Mol Cell Biol 12, 757763. 
17 Piguet PF, Vesin C, Guo J, Donati Y \& Barazzone C (1998) TNF induced enterocyte apoptosis in mice is mediated by the TNF receptor 1 and does not require p53. Eur J Immunol 28, 34993505.

18 Miron N \& Cristea V (2012) Enterocytes: active cells in tolerance to food and microbial antigens in the gut. Clin Exp Immunol 167, 405412.

19 Kato T \& Owen RL (2005) Structure and function of intestinal mucosal epithelium. In Mucosal Immunology, 3rd edn. pp. 131 151. Elsevier Academic Press, Burlington, MA.

20 Gonzalez Mariscal L, Tapia R \& Chamorro D (2008) Crosstalk of tight junction components with signaling pathways. Biochim Biophys Acta 1778, 729756.

21 Matter K \& Balda MS (2003) Signalling to and from tight junctions. Nat Rev Mol Cell Biol 4, 225236.

22 Johansson ME, Sjovall H \& Hansson GC (2013) The gastrointestinal mucus system in health and disease. Nat Rev Gastroenterol Hepatol 10, 352361.

23 Williams JM, Duckworth CA, Burkitt MD, Watson AJ, Campbell BJ \& Pritchard DM (2015) Epithelial cell shedding and barrier function: a matter of life and death at the small intestinal villus tip. Vet Pathol 52, 445455.

24 Rupani B, Caputo FJ, Watkins AC, Vega D, Magnotti LJ, Lu Q, da Xu Z \& Deitch EA (2007) Relationship between disruption of the unstirred mucus layer and intestinal restitution in loss of gut barrier function after trauma hemorrhagic shock. Surgery 141, 481489.

25 Zarepour M, Bhullar K, Montero M, Ma C, Huang T, Velcich A, Xia L \& Vallance BA (2013) The mucin Muc2 limits pathogen burdens and epithelial barrier dysfunction during Salmonella enterica serovar Typhimurium colitis. Infect Immun 81, 36723683.

26 Keshav S, Lawson L, Chung LP, Stein M, Perry VH \& Gordon S (1990) Tumor necrosis factor mRNA localized to Paneth cells of normal murine intestinal epithelium by in situ hybridization. J Exp Med 171, 327332.

27 Gerbe F, Legraverend C \& Jay P (2012) The intestinal epithelium tuft cells: specification and function. Cell Mol Life Sci 69, 29072917.

28 Brunner T, Arnold D, Wasem C, Herren S \& Frutschi C (2001) Regulation of cell death and survival in intestinal intraepithelial lymphocytes. Cell Death Differ 8, 706714.

29 Cheroutre H, Lambolez F \& Mucida D (2011) The light and dark sides of intestinal intraepithelial lymphocytes. Nat Rev Immunol 11, 445456.

30 Haegebarth A \& Clevers H (2009) Wnt signaling, lgr5, and stem cells in the intestine and skin. Am J Pathol 174, 715721.

31 Mayhew TM, Myklebust R, Whybrow A \& Jenkins R (1999) Epithelial integrity, cell death and cell loss in mammalian small intestine. Histol Histopathol 14, 257 267.
32 Nunes T, Bernardazzi C \& de Souza HS (2014) Cell death and inflammatory bowel diseases: apoptosis, necrosis, and autophagy in the intestinal epithelium. Biomed Res Int 2014, 218493.

33 Grossmann J, Maxson JM, Whitacre CM, Orosz DE, Berger NA, Fiocchi C \& Levine AD (1998) New isolation technique to study apoptosis in human intestinal epithelial cells. Am J Pathol 153, 5362.

34 Kiesslich R, Duckworth CA, Moussata D, Gloeckner A, Lim LG, Goetz M, Pritchard DM, Galle PR, Neurath MF \& Watson AJ (2012) Local barrier dysfunction identified by confocal laser endomicroscopy predicts relapse in inflammatory bowel disease. Gut 61, 11461153.

35 Deinert K, Kiesslich R, Vieth M, Neurath MF \& Neuhaus H (2007) In vivo microvascular imaging of early squamous cell cancer of the esophagus by confocal laser endomicroscopy. Endoscopy 39, 366368.

36 Guan Y, Watson AJ, Marchiando AM, Bradford E, Shen L, Turner JR \& Montrose MH (2011) Redistribution of the tight junction protein $\mathrm{ZO} 1$ during physiological shedding of mouse intestinal epithelial cells. Am J Physiol Cell Physiol 300, C1404 C1414.

37 Watson AJ, Duckworth CA, Guan Y \& Montrose MH (2009) Mechanisms of epithelial cell shedding in the Mammalian intestine and maintenance of barrier function. Ann N Y Acad Sci 1165, 135142.

38 Madara JL (1990) Maintenance of the macromolecular barrier at cell extrusion sites in intestinal epithelium: physiological rearrangement of tight junctions. $J$ Membr Biol 116, 177184.

39 Watson AJ \& Hughes KR (2012) TNF alpha induced intestinal epithelial cell shedding: implications for intestinal barrier function. Ann N Y Acad Sci 1258, 18.

40 Watson AJ, Chu S, Sieck L, Gerasimenko O, Bullen T, Campbell F, McKenna M, Rose T \& Montrose MH (2005) Epithelial barrier function in vivo is sustained despite gaps in epithelial layers. Gastroenterology 129, 902912.

41 Beeman N, Webb PG \& Baumgartner HK (2012) Occludin is required for apoptosis when claudin claudin interactions are disrupted. Cell Death Dis 3, e273.

42 Bullen TF, Forrest S, Campbell F, Dodson AR, Hershman MJ, Pritchard DM, Turner JR, Montrose MH \& Watson AJ (2006) Characterization of epithelial cell shedding from human small intestine. Lab Invest 86, 10521063.

43 Marchiando AM, Shen L, Graham WV, Edelblum KL, Duckworth CA, Guan Y, Montrose MH, Turner JR \& Watson AJ (2011) The epithelial barrier is maintained by in vivo tight junction expansion during pathologic intestinal epithelial shedding. Gastroenterology 140, 1208 1218, e1 2. 
44 Beausejour M, Thibodeau S, Demers MJ, Bouchard V, Gauthier R, Beaulieu JF \& Vachon PH (2013) Suppression of anoikis in human intestinal epithelial cells: differentiation state selective roles of alpha2beta1, alpha3beta1, alpha5beta1, and alpha6beta4 integrins. BMC Cell Biol 14, 53.

45 Levine AD (2000) Apoptosis: implications for inflammatory bowel disease. Inflamm Bowel Dis 6, 191205.

46 Grabinger T, Luks L, Kostadinova F, Zimberlin C, Medema JP, Leist M \& Brunner T (2014) Ex vivo culture of intestinal crypt organoids as a model system for assessing cell death induction in intestinal epithelial cells and enteropathy. Cell Death Dis $\mathbf{5}$, e1228.

47 Paoli P, Giannoni E \& Chiarugi P (2013) Anoikis molecular pathways and its role in cancer progression. Biochim Biophys Acta 1833, 34813498.

48 Puthalakath H, Villunger A, O'Reilly LA, Beaumont JG, Coultas L, Cheney RE, Huang DC \& Strasser A (2001) Bmf: a proapoptotic BH3 only protein regulated by interaction with the myosin $\mathrm{V}$ actin motor complex, activated by anoikis. Science $\mathbf{2 9 3}$, 18291832.

49 Reginato MJ, Mills KR, Paulus JK, Lynch DK, Sgroi DC, Debnath J, Muthuswamy SK \& Brugge JS (2003) Integrins and EGFR coordinately regulate the pro apoptotic protein Bim to prevent anoikis. Nat Cell Biol 5, 733740.

50 Piguet PF, Vesin C, Donati Y \& Barazzone C (1999) TNF induced enterocyte apoptosis and detachment in mice: induction of caspases and prevention by a caspase inhibitor, ZVAD fmk. Lab Invest 79, 495500.

51 Chowdhury I, Tharakan B \& Bhat GK (2008) Caspases an update. Comp Biochem Physiol B Biochem Mol Biol 151, 1027.

52 Schneider Jakob S, Corazza N, Badmann A, Sidler D, Stuber Roos R, Keogh A, Frese S, Tschan M \& Brunner T (2010) Synergistic induction of cell death in liver tumor cells by TRAIL and chemotherapeutic drugs via the $\mathrm{BH} 3$ only proteins Bim and Bid. Cell Death Dis 1, e86.

53 Tang Y, Swartz Basile DA, Swietlicki EA, Yi L, Rubin DC \& Levin MS (2004) Bax is required for resection induced changes in apoptosis, proliferation, and members of the extrinsic cell death pathways. Gastroenterology 126, 220230.

54 Youle RJ \& Strasser A (2008) The BCL 2 protein family: opposing activities that mediate cell death. Nat Rev Mol Cell Biol 9, 4759.

55 Kelekar A \& Thompson CB (1998) Bcl 2 family proteins: the role of the $\mathrm{BH} 3$ domain in apoptosis. Trends Cell Biol 8, 324330.

56 Lindsay J, Esposti MD \& Gilmore AP (2011) Bcl 2 proteins and mitochondria specificity in membrane targeting for death. Biochim Biophys Acta 1813, 532 539.

57 Merritt AJ, Potten CS, Watson AJ, Loh DY, Nakayama K, Nakayama K \& Hickman JA (1995) Differential expression of bcl 2 in intestinal epithelia. Correlation with attenuation of apoptosis in colonic crypts and the incidence of colonic neoplasia. J Cell Sci 108 (Pt 6), 22612271.

58 Scorrano L, Oakes SA, Opferman JT, Cheng EH, Sorcinelli MD, Pozzan T \& Korsmeyer SJ (2003) BAX and BAK regulation of endoplasmic reticulum $\mathrm{Ca} 2+$ : a control point for apoptosis. Science 300, 135139.

59 Hausmann M, Leucht K, Ploner C, Kiessling S, Villunger A, Becker H, Hofmann C, Falk W, Krebs M, Kellermeier S et al. (2011) BCL 2 modifying factor (BMF) is a central regulator of anoikis in human intestinal epithelial cells. $J$ Biol Chem 286, 26533 26540.

60 Rosen K, Rak J, Leung T, Dean NM, Kerbel RS \& Filmus J (2000) Activated Ras prevents downregulation of $\mathrm{Bcl} \mathrm{X}(\mathrm{L})$ triggered by detachment from the extracellular matrix. A mechanism of Ras induced resistance to anoikis in intestinal epithelial cells. J Cell Biol 149, 447456.

61 Haraguchi M, Torii S, Matsuzawa S, Xie Z, Kitada S, Krajewski S, Yoshida H, Mak TW \& Reed JC (2000) Apoptotic protease activating factor 1 (Apaf 1) independent cell death suppression by Bcl 2. J Exp Med 191, 17091720.

62 Bratton SB \& Salvesen GS (2010) Regulation of the Apaf 1 caspase 9 apoptosome. J Cell Sci 123, 3209 3214.

63 Kim HE, Du F, Fang M \& Wang X (2005) Formation of apoptosome is initiated by cytochrome $\mathrm{c}$ induced dATP hydrolysis and subsequent nucleotide exchange on Apaf 1. Proc Natl Acad Sci USA 102, 1754517550.

64 Li P, Nijhawan D, Budihardjo I, Srinivasula SM, Ahmad M, Alnemri ES \& Wang X (1997) Cytochrome c and dATP dependent formation of Apaf 1/caspase 9 complex initiates an apoptotic protease cascade. Cell 91, 479489.

65 Pop C, Timmer J, Sperandio S \& Salvesen GS (2006) The apoptosome activates caspase 9 by dimerization. Mol Cell 22, 269275.

66 Aoudjit F \& Vuori K (2001) Matrix attachment regulates Fas induced apoptosis in endothelial cells: a role for c flip and implications for anoikis. J Cell Biol 152, 633643 .

67 Rytomaa M, Martins LM \& Downward J (1999) Involvement of FADD and caspase 8 signalling in detachment induced apoptosis. Curr Biol 9, 10431046.

68 French LE \& Tschopp J (2003) Protein based therapeutic approaches targeting death receptors. Cell Death Differ 10, 117123. 
69 Lavrik I, Golks A \& Krammer PH (2005) Death receptor signaling. J Cell Sci 118, 265267.

70 Ashkenazi A \& Dixit VM (1998) Death receptors: signaling and modulation. Science 281, 13051308.

71 Lavrik IN \& Krammer PH (2012) Regulation of CD95/Fas signaling at the DISC. Cell Death Differ 19, 3641.

72 Aggarwal BB (2003) Signalling pathways of the TNF superfamily: a double edged sword. Nat Rev Immunol 3, 745756.

73 Siegel RM, Martin DA, Zheng L, Ng SY, Bertin J, Cohen J \& Lenardo MJ (1998) Death effector filaments: novel cytoplasmic structures that recruit caspases and trigger apoptosis. J Cell Biol 141, 12431253.

74 Dickens LS, Boyd RS, Jukes Jones R, Hughes MA, Robinson GL, Fairall L, Schwabe JW, Cain K \& Macfarlane M (2012) A death effector domain chain DISC model reveals a crucial role for caspase 8 chain assembly in mediating apoptotic cell death. Mol Cell 47, 291305.

75 Schleich K, Warnken U, Fricker N, Ozturk S, Richter P, Kammerer K, Schnolzer M, Krammer PH \& Lavrik IN (2012) Stoichiometry of the CD95 death inducing signaling complex: experimental and modeling evidence for a death effector domain chain model. Mol Cell 47, 306319.

76 Budd RC, Yeh WC \& Tschopp J (2006) cFLIP regulation of lymphocyte activation and development. Nat Rev Immunol 6, 196204.

77 Piao X, Komazawa Sakon S, Nishina T, Koike M, Piao JH, Ehlken H, Kurihara H, Hara M, Van Rooijen N, Schutz G et al. (2012) c FLIP maintains tissue homeostasis by preventing apoptosis and programmed necrosis. Sci Signal 5, ra93.

78 Seidelin JB, Coskun M, Vainer B, Riis L, Soendergaard C \& Nielsen OH (2013) ERK controls epithelial cell death receptor signalling and cellular FLICE like inhibitory protein (c FLIP) in ulcerative colitis. J Mol Med (Berl) 91, 839849.

79 Slebioda TJ \& Kmiec Z (2014) Tumour necrosis factor superfamily members in the pathogenesis of inflammatory bowel disease. Mediators Inflamm 2014, 325129.

80 Bamias G, Kaltsa G, Siakavellas SI, Gizis M, Margantinis G, Zampeli E, Vafiadis Zoumboulis I, Michopoulos S, Daikos GL \& Ladas SD (2012) Differential expression of the TL1A/DcR3 system of TNF/TNFR like proteins in large vs. small intestinal Crohn's disease. Dig Liver Dis 44, 3036.

81 Funke B, Autschbach F, Kim S, Lasitschka F, Strauch U, Rogler G, Gdynia G, Li L, Gretz N, Macher Goeppinger S et al. (2009) Functional characterisation of decoy receptor 3 in Crohn's disease. Gut 58, 483491.
82 Luthi AU \& Martin SJ (2007) The CASBAH: a searchable database of caspase substrates. Cell Death Differ 14, 641650.

83 Walsh JG, Cullen SP, Sheridan C, Luthi AU, Gerner C \& Martin SJ (2008) Executioner caspase 3 and caspase 7 are functionally distinct proteases. Proc Natl Acad Sci USA 105, 1281512819.

84 Hunter AM, LaCasse EC \& Korneluk RG (2007) The inhibitors of apoptosis (IAPs) as cancer targets. Apoptosis 12, 15431568.

85 Eckelman BP \& Salvesen GS (2006) The human anti apoptotic proteins cIAP1 and cIAP2 bind but do not inhibit caspases. J Biol Chem 281, 32543260.

86 Liu Z, Li H, Wu X, Yoo BH, Yan SR, Stadnyk AW, Sasazuki T, Shirasawa S, LaCasse EC, Korneluk RG et al. (2006) Detachment induced upregulation of XIAP and cIAP2 delays anoikis of intestinal epithelial cells. Oncogene 25, 76807690.

87 Yoo BH, Berezkin A, Wang Y, Zagryazhskaya A \& Rosen KV (2012) Tumor suppressor protein kinase Chk2 is a mediator of anoikis of intestinal epithelial cells. Int J Cancer 131, 357366.

88 Croitoru K \& Zhou P (2004) T cell induced mucosal damage in the intestine. Curr Opin Gastroenterol 20, 581586.

89 Lin T, Brunner T, Tietz B, Madsen J, Bonfoco E, Reaves M, Huflejt M \& Green DR (1998) Fas ligand mediated killing by intestinal intraepithelial lymphocytes. Participation in intestinal graft versus host disease. J Clin Invest 101, 570577.

90 Offit PA, Cunningham SL \& Dudzik KI (1991) Memory and distribution of virus specific cytotoxic T lymphocytes (CTLs) and CTL precursors after rotavirus infection. J Virol 65, 13181324.

91 Neurath MF (2014) Cytokines in inflammatory bowel disease. Nat Rev Immunol 14, 329342.

92 Noth R, Stuber E, Hasler R, Nikolaus S, Kuhbacher T, Hampe J, Bewig B, Schreiber S \& Arlt A (2012) Anti TNF alpha antibodies improve intestinal barrier function in Crohn's disease. J Crohns Colitis 6, 464469.

93 Moore JV (1986) The 'gastrointestinal syndrome' after chemotherapy: inferences from mouse survival time, and from histologically and clonogenically defined cell death in intestinal crypts. Br J Cancer Suppl 7, 1619.

94 Jin S (2012) Role of p53 in anticancer drug treatment and radiation induced injury in normal small intestine. Cancer Biol Med 9, 18.

95 Xian CJ (2003) Roles of growth factors in chemotherapy induced intestinal mucosal damage repair. Curr Pharm Biotechnol 4, 260269.

96 Branzei D \& Foiani M (2008) Regulation of DNA repair throughout the cell cycle. Nat Rev Mol Cell Biol 9, 297308 . 
97 Bartek J \& Lukas J (2007) DNA damage checkpoints: from initiation to recovery or adaptation. Curr Opin Cell Biol 19, 238245.

98 Meek DW (2009) Tumour suppression by p53: a role for the DNA damage response? Nat Rev Cancer 9, 714723.

99 Riley T, Sontag E, Chen P \& Levine A (2008) Transcriptional control of human p53 regulated genes. Nat Rev Mol Cell Biol 9, 402412.

100 Clarke AR, Gledhill S, Hooper ML, Bird CC \& Wyllie AH (1994) p53 dependence of early apoptotic and proliferative responses within the mouse intestinal epithelium following gamma irradiation. Oncogene $\mathbf{9}$, 17671773

101 Merritt AJ, Potten CS, Kemp CJ, Hickman JA, Balmain A, Lane DP \& Hall PA (1994) The role of p53 in spontaneous and radiation induced apoptosis in the gastrointestinal tract of normal and p53 deficient mice. Cancer Res 54, 614617.

102 Nakano K \& Vousden KH (2001) PUMA, a novel proapoptotic gene, is induced by p53. Mol Cell 7, 683694.

103 Oda E, Ohki R, Murasawa H, Nemoto J, Shibue T, Yamashita $\mathrm{T}$, Tokino $\mathrm{T}$, Taniguchi $\mathrm{T} \&$ Tanaka $\mathrm{N}$ (2000) Noxa, a BH3 only member of the Bcl 2 family and candidate mediator of p53 induced apoptosis. Science 288, 10531058.

104 Erlacher M, Michalak EM, Kelly PN, Labi V, Niederegger H, Coultas L, Adams JM, Strasser A \& Villunger A (2005) BH3 only proteins Puma and Bim are rate limiting for gamma radiation and glucocorticoid induced apoptosis of lymphoid cells in vivo. Blood 106, 41314138.

105 Miyashita T \& Reed JC (1995) Tumor suppressor p53 is a direct transcriptional activator of the human bax gene. Cell 80, 293299.

106 Pietrzak M \& Puzianowska Kuznicka M (2008) p53 dependent repression of the human MCL 1 gene encoding an anti apoptotic member of the BCL 2 family: the role of $\mathrm{Sp} 1$ and of basic transcription factor binding sites in the MCL 1 promoter. Biol Chem 389, 383393.

107 Hill R, Madureira PA, Waisman DM \& Lee PW (2011) DNA PKCS binding to p53 on the p21WAF1/ CIP1 promoter blocks transcription resulting in cell death. Oncotarget 2, 10941108.

108 Michalak EM, Villunger A, Adams JM \& Strasser A (2008) In several cell types tumour suppressor p53 induces apoptosis largely via Puma but Noxa can contribute. Cell Death Differ 15, 10191029.

109 Dirisina R, Katzman RB, Goretsky T, Managlia E, Mittal N, Williams DB, Qiu W, Yu J, Chandel NS, Zhang L et al. (2011) p53 and PUMA independently regulate apoptosis of intestinal epithelial cells in patients and mice with colitis. Gastroenterology 141, 10361045 .
110 Qiu W, Wu B, Wang X, Buchanan ME, Regueiro MD, Hartman DJ, Schoen RE, Yu J \& Zhang L (2011) PUMA mediated intestinal epithelial apoptosis contributes to ulcerative colitis in humans and mice. $J$ Clin Invest 121, 17221732.

111 Hock AK \& Vousden KH (2012) Tumor suppression by p53: fall of the triumvirate? Cell 149, 11831185.

112 Goretsky T, Dirisina R, Sinh P, Mittal N, Managlia E, Williams DB, Posca D, Ryu H, Katzman RB \& Barrett TA (2012) p53 mediates TNF induced epithelial cell apoptosis in IBD. Am J Pathol 181, 13061315.

113 Merritt AJ, Allen TD, Potten CS \& Hickman JA (1997) Apoptosis in small intestinal epithelial from p53 null mice: evidence for a delayed, p53 independent G2/M associated cell death after gamma irradiation. Oncogene 14, 27592766.

114 Roos WP \& Kaina B (2006) DNA damage induced cell death by apoptosis. Trends Mol Med 12, 440450.

115 Komarova EA, Kondratov RV, Wang K, Christov K, Golovkina TV, Goldblum JR \& Gudkov AV (2004) Dual effect of p53 on radiation sensitivity in vivo: p53 promotes hematopoietic injury, but protects from gastro intestinal syndrome in mice. Oncogene 23, 32653271.

116 Husain KD \& Coopersmith CM (2003) Role of intestinal epithelial apoptosis in survival. Curr Opin Crit Care 9, 159163.

117 Chopra M, Brandl A, Siegmund D, Mottok A, Schafer V, Biehl M, Kraus S, Bauerlein CA, Ritz M, Mattenheimer K et al. (2015) Blocking TWEAK Fn14 interaction inhibits hematopoietic stem cell transplantation induced intestinal cell death and reduces GvHD. Blood 126, 437444.

118 Merger M, Viney JL, Borojevic R, Steele Norwood D, Zhou P, Clark DA, Riddell R, Maric R, Podack ER \& Croitoru K (2002) Defining the roles of perforin, Fas/FasL, and tumour necrosis factor alpha in $\mathrm{T}$ cell induced mucosal damage in the mouse intestine. Gut 51, 155163.

119 Wasem C, Frutschi C, Arnold D, Vallan C, Lin T, Green DR, Mueller C \& Brunner T (2001) Accumulation and activation induced release of preformed Fas (CD95) ligand during the pathogenesis of experimental graft versus host disease. J Immunol 167, 29362941.

120 Xiao S, Sung SS, Fu SM \& Ju ST (2003) Combining Fas mutation with interleukin 2 deficiency prevents Colitis and Lupus: implicating interleukin 2 for auto reactive $\mathrm{T}$ cell expansion and Fas ligand for colon epithelial cell death. J Biol Chem 278, 5273052738.

121 Park SM, Chen L, Zhang M, Ashton Rickardt P, Turner JR \& Peter ME (2010) CD95 is cytoprotective for intestinal epithelial cells in colitis. Inflamm Bowel Dis 16, 10631070. 
122 Cullen SP \& Martin SJ (2015) Fas and TRAIL 'death receptors' as initiators of inflammation: implications for cancer. Semin Cell Dev Biol 39, 2634.

123 Pinkoski MJ, Droin NM, Lin T, Genestier L, Ferguson TA \& Green DR (2002) Nonlymphoid Fas ligand in peptide induced peripheral lymphocyte deletion. Proc Natl Acad Sci USA 99, 1617416179.

124 Walczak H, Miller RE, Ariail K, Gliniak B, Griffith TS, Kubin M, Chin W, Jones J, Woodward A, Le T et al. (1999) Tumoricidal activity of tumor necrosis factor related apoptosis inducing ligand in vivo. Nat Med 5, 157163.

125 Ashkenazi A \& Herbst RS (2008) To kill a tumor cell: the potential of proapoptotic receptor agonists. J Clin Invest 118, 19791990.

126 von Karstedt S, Conti A, Nobis M, Montinaro A, Hartwig T, Lemke J, Legler K, Annewanter F, Campbell AD, Taraborrelli L et al. (2015) Cancer cell autonomous TRAIL R signaling promotes KRAS driven cancer progression, invasion, and metastasis. Cancer Cell 27, 561573.

127 Corazza N, Jakob S, Schaer C, Frese S, Keogh A, Stroka D, Kassahn D, Torgler R, Mueller C, Schneider P et al. (2006) TRAIL receptor mediated JNK activation and Bim phosphorylation critically regulate Fas mediated liver damage and lethality. $J$ Clin Invest 116, 24932499.

128 Corazza N, Kassahn D, Jakob S, Badmann A \& Brunner T (2009) TRAIL induced apoptosis: between tumor therapy and immunopathology. Ann N Y Acad Sci 1171, 5058.

129 Strater J, Walczak H, Pukrop T, Von Muller L, Hasel C, Kornmann M, Mertens T \& Moller P (2002) TRAIL and its receptors in the colonic epithelium: a putative role in the defense of viral infections. Gastroenterology 122, 659666.

130 Brost S, Koschny R, Sykora J, Stremmel W, Lasitschka F, Walczak H \& Ganten TM (2010) Differential expression of the TRAIL/TRAIL receptor system in patients with inflammatory bowel disease. Pathol Res Pract 206, 4350.

131 Kaufmann T, Jost PJ, Pellegrini M, Puthalakath H, Gugasyan R, Gerondakis S, Cretney E, Smyth MJ, Silke J, Hakem R et al. (2009) Fatal hepatitis mediated by tumor necrosis factor TNFalpha requires caspase 8 and involves the $\mathrm{BH} 3$ only proteins Bid and Bim. Immunity 30, 5666.

132 Wang K, Han G, Dou Y, Wang Y, Liu G, Wang R, Xiao H, Li X, Hou C, Shen B et al. (2012) Opposite role of tumor necrosis factor receptors in dextran sulfate sodium induced colitis in mice. PLoS One 7, e52924.

133 Corazza N, Eichenberger S, Eugster HP \& Mueller C (1999) Nonlymphocyte derived tumor necrosis factor is required for induction of colitis in recombination activating gene (RAG)2( / ) mice upon transfer of CD4(+)CD45RB(hi) T cells. J Exp Med 190, 1479 1492.

134 Wirtz S \& Neurath MF (2007) Mouse models of inflammatory bowel disease. Adv Drug Deliv Rev 59, 10731083.

135 Suzuki T (2013) Regulation of intestinal epithelial permeability by tight junctions. Cell Mol Life Sci 70, 631659.

136 Schneider Brachert W, Tchikov V, Neumeyer J, Jakob M, Winoto Morbach S, Held Feindt J, Heinrich M, Merkel O, Ehrenschwender M, Adam D et al. (2004) Compartmentalization of TNF receptor 1 signaling: internalized TNF receptosomes as death signaling vesicles. Immunity 21, 415428.

137 Wang L, Du F \& Wang X (2008) TNF alpha induces two distinct caspase 8 activation pathways. Cell 133, 693703.

138 Micheau O \& Tschopp J (2003) Induction of TNF receptor I mediated apoptosis via two sequential signaling complexes. Cell 114, 181190.

139 Sun C, Cai M, Gunasekera AH, Meadows RP, Wang $\mathrm{H}$, Chen J, Zhang H, Wu W, Xu N, Ng SC et al. (1999) NMR structure and mutagenesis of the inhibitor of apoptosis protein XIAP. Nature 401, 818 822.

140 Haas TL, Emmerich CH, Gerlach B, Schmukle AC, Cordier SM, Rieser E, Feltham R, Vince J, Warnken $\mathrm{U}$, Wenger T et al. (2009) Recruitment of the linear ubiquitin chain assembly complex stabilizes the TNF $\mathrm{R} 1$ signaling complex and is required for TNF mediated gene induction. Mol Cell 36, 831844.

141 Varfolomeev EE \& Ashkenazi A (2004) Tumor necrosis factor: an apoptosis JuNKie? Cell 116, 491 497.

142 Guma M, Stepniak D, Shaked H, Spehlmann ME, Shenouda S, Cheroutre H, Vicente Suarez I, Eckmann L, Kagnoff MF \& Karin M (2011) Constitutive intestinal NF kappaB does not trigger destructive inflammation unless accompanied by MAPK activation. J Exp Med 208, 18891900.

143 Karrasch T, Steinbrecher KA, Allard B, Baldwin AS \& Jobin C (2006) Wound induced p38MAPK dependent histone $\mathrm{H} 3$ phosphorylation correlates with increased COX 2 expression in enterocytes. $J$ Cell Physiol 207, 809815.

144 Hehlgans T \& Pfeffer K (2005) The intriguing biology of the tumour necrosis factor/tumour necrosis factor receptor superfamily: players, rules and the games. Immunology 115, 120.

145 Roulis M, Armaka M, Manoloukos M, Apostolaki M \& Kollias G (2011) Intestinal epithelial cells as producers but not targets of chronic TNF suffice to cause murine Crohn like pathology. Proc Natl Acad Sci USA 108, 53965401. 
146 Seidelin JB, Vainer B, Andresen L \& Nielsen OH (2007) Upregulation of cIAP2 in regenerating colonocytes in ulcerative colitis. Virchows Arch 451, 10311038

147 Lavrik IN, Mock T, Golks A, Hoffmann JC, Baumann S \& Krammer PH (2008) CD95 stimulation results in the formation of a novel death effector domain protein containing complex. $J$ Biol Chem 283, 2640126408.

148 Vince JE, Chau D, Callus B, Wong WW, Hawkins CJ, Schneider P, McKinlay M, Benetatos CA, Condon SM, Chunduru SK et al. (2008) TWEAK FN14 signaling induces lysosomal degradation of a cIAP1 TRAF2 complex to sensitize tumor cells to TNFalpha. J Cell Biol 182, 171184.

149 Wicovsky A, Salzmann S, Roos C, Ehrenschwender M, Rosenthal T, Siegmund D, Henkler F, Gohlke F, Kneitz C \& Wajant H (2009) TNF like weak inducer of apoptosis inhibits proinflammatory TNF receptor 1 signaling. Cell Death Differ 16, 14451459.

150 Vandenabeele P, Galluzzi L, Vanden Berghe T \& Kroemer G (2010) Molecular mechanisms of necroptosis: an ordered cellular explosion. Nat Rev Mol Cell Biol 11, 700714.

151 Christofferson DE \& Yuan J (2010) Necroptosis as an alternative form of programmed cell death. Curr Opin Cell Biol 22, 263268.

152 Galluzzi L, Kepp O \& Kroemer G (2009) RIP kinases initiate programmed necrosis. $J$ Mol Cell Biol 1, 810.

153 Sun X, Yin J, Starovasnik MA, Fairbrother WJ \& Dixit VM (2002) Identification of a novel homotypic interaction motif required for the phosphorylation of receptor interacting protein (RIP) by RIP3. $J$ Biol Chem 277, 95059511.

154 Vandenabeele P, Declercq W, Van Herreweghe F \& Vanden Berghe $T$ (2010) The role of the kinases RIP1 and RIP3 in TNF induced necrosis. Sci Signal 3, re4.
155 Micheau O, Lens S, Gaide O, Alevizopoulos K \& Tschopp J (2001) NF kappaB signals induce the expression of c FLIP. Mol Cell Biol 21, 52995305.

156 Fricker N, Beaudouin J, Richter P, Eils R, Krammer PH \& Lavrik IN (2010) Model based dissection of CD95 signaling dynamics reveals both a pro and antiapoptotic role of c FLIPL. J Cell Biol 190, 377389.

157 Krueger A, Schmitz I, Baumann S, Krammer PH \& Kirchhoff S (2001) Cellular FLICE inhibitory protein splice variants inhibit different steps of caspase 8 activation at the CD95 death inducing signaling complex. J Biol Chem 276, 2063320640.

158 Chang L, Kamata H, Solinas G, Luo JL, Maeda S, Venuprasad K, Liu YC \& Karin M (2006) The E3 ubiquitin ligase itch couples JNK activation to TNFalpha induced cell death by inducing c FLIP(L) turnover. Cell 124, 601613.

159 Han J, Zhong CQ \& Zhang DW (2011) Programmed necrosis: backup to and competitor with apoptosis in the immune system. Nat Immunol 12, 11431149.

160 Takahashi N, Vereecke L, Bertrand MJ, Duprez L, Berger SB, Divert T, Goncalves A, Sze M, Gilbert B, Kourula S et al. (2014) RIPK1 ensures intestinal homeostasis by protecting the epithelium against apoptosis. Nature 513, 9599.

161 Wine E (2014) Should we be treating the bugs instead of cytokines and T cells? Dig Dis 32, 403409.

162 Martinon F, Gaide O, Petrilli V, Mayor A \& Tschopp J (2007) NALP inflammasomes: a central role in innate immunity. Semin Immunopathol 29, 213229.

163 Mocarski ES, Upton JW \& Kaiser WJ (2012) Viral infection and the evolution of caspase 8 regulated apoptotic and necrotic death pathways. Nat Rev Immunol 12, 7988.

164 Abreu MT (2010) Toll like receptor signalling in the intestinal epithelium: how bacterial recognition shapes intestinal function. Nat Rev Immunol 10, 131144. 